ENSAYO

\title{
LA TRANSFORMACIÓN DE LA DEMOCRACIA COMO MODELO DE ORIENTACIÓN DE LAS SOCIEDADES COMPLEJAS*
}

\author{
Helmut Willke
}

Helmut Willke (1945) es actualmente uno de los principales representantes del pensamiento sistémico en sociología. Estrecho colaborador de Niklas Luhmann durante los años ochenta en la Universidad de Bielefeld, el interés de Willke por una teoría de sistemas que se hiciera cargo de problemas concretos de las sociedades modernas lo llevó a desarrollar una línea de pensamiento sistémico heterodoxa caracterizada fundamentalmente por la idea de una intervención "no instructiva” en sistemas sociales autónomos. Mientras Luhmann sostuvo con énfasis la imposibilidad de intervención de un sistema autónomo desde su entorno, para Willke la intervención será exitosa en tanto tenga sentido para las propiedades autónomas del sistema

Helmut Willke (1945) es, desde 1983, profesor de la Facultad de Sociología de la Universidad de Bielefeld en el área de Planeación y Teoría de la Decisión. Obtuvo en 1994 el Premio Leibniz de la Comunidad de Investigación Alemana. Entre sus más importantes obras se encuentran Ironie des Staates (1992), Systemtheorie II: Interventionstheorie (1994), Systemtheorie III: Steuerungstheorie (1995), Systemisches Wissensmanagement (1998) y Heterotopia (2003). Número postal 100 131, D-33501, Bielefeld.

* “Transformation der Demokratie als Steuerungsmodell hochkomplexer Gesellschaften”, publicado originalmente en alemán, en Soziale Systeme, Núm. 2, 1995, pp. 283-300. Traducido al castellano por Aldo Mascareño y reproducido en esta edición con la debida autorización del autor. 
que se busca regular. El texto que se presenta a continuación expresa esta idea en relación con la democracia: si ella busca mantener alguna capacidad de orientación de la sociedad moderna, debe renunciar a toda pretensión de control y sustituirla por una gramática de la coordinación. La democracia se transforma de este modo en un modelo de seducción probablemente más estratégico, pero de todos modos menos impositivo.

\section{Introducción}

\section{A} mación, el llamado segundo mundo se ha visto enfrentado al reconocimiento de una apertura democrática inevitable. El tercer mundo, por su parte, consciente de la diversidad de sus problemas, ha estado constantemente sujeto a una transformación paralizante. Tan sólo el primer mundo alcanza a vislumbrar los inminentes cambios a los que obliga un mundo multipolar, una 'paz fría' (Garten, 1992) y la independencia de los sistemas complejos. El siguiente texto intenta probar que, luego del colapso de la confrontación Este-Oeste, la democracia ha sido relevada de su posición sagrada como modelo de orientación (Steuerungsmodell) ${ }^{\mathrm{a}}$ de las sociedades complejas y es expuesta a un frío examen relativo a su capacidad de establecer lineamientos de orientación socialmente vinculantes. En el origen de tal escéptico cuestionamiento de la democracia es posible encontrar una serie de problemas asociados a los mecanismos de orientación social, problemas causados por los cambios de los contextos globales y a los cuales las sociedades modernas se ven enfrentadas. Me refiero a los nuevos problemas de la política, el mercado y la jerarquía:

1. El desafío de la política se origina en un desplazamiento del balance de poder de los sistemas sociales que se encontraban bajo su dominio. Esto deriva en estrategias políticas que no reflejan los pro-

${ }^{a}$ En su interpretación sistémica, la palabra alemana Steuerung puede ser traducida como orientación o conducción. En esta traducción, y luego de su análisis con el autor del texto, hemos privilegiado el concepto de orientación. El término regulación ha sido desechado básicamente por dos razones: en primer lugar, éste dispone de un vocablo preciso en alemán: la palabra de origen latino Regulierung, a la que Willke asigna un sentido distinto e incluso contrapuesto a Steuerung. En segundo lugar, el debate en torno a la regulación tiene ya una larga tradición al interior de la teoría económica. En apoyo a nuestra elección puede citarse al propio Willke, quien en inglés utiliza la palabra guidance para significar Steuerung, desechando incluso el término steering, en apariencia más cercano. (N. del T.) 


\author{
blemas nacionales e internacionales a los cuales tales estrategias \\ apuntan.
}

2. El desafío del mercado se transforma en un problema de la democracia toda vez que la lógica de mercado opera globalmente, mientras que las decisiones políticas sólo pueden aspirar a un alcance territorialmente circunscrito y a una legitimidad limitada.

3. El desafío de la jerarquía se manifiesta en la escasa capacidad de una arquitectura jerárquica para el desarrollo de modelos de resolución de problemas locales y globales. La democracia, en tanto forma ${ }^{\mathrm{b}}$, es susceptible de crítica toda vez que ella está ligada estrechamente a la jerarquía, sea en su interior o en sus relaciones externas.

Aclararé estos tres aspectos en referencia a los riesgos que ellos implican y señalaré, en la sección 4, una dirección de su posible transformación.

\title{
1. El desafío de la política
}

Concluido el mito socialista, no sólo el capitalismo como forma económica sino también la democracia como forma operativa de las sociedades seculares modernas vuelven una y otra vez sobre sí mismos. La pregunta es si la democracia, hacia fines del siglo XX, en cuanto estructura auto-organi-

${ }^{\text {b }}$ El autor utiliza el concepto de forma en el sentido técnico de la teoría de sistemas autorreferenciales, esto es, como un espacio dividido en dos por una distinción. Su origen está en el cálculo matemático de George Spencer-Brown y su intento de constructivismo operacional en Laws of Form, cuyo mandato inicial señala: "Trace una distinción. Llame al espacio separado por la distinción y al contenido de ese espacio la forma de la distinción” (Spencer-Brown, G., Laws of Form, New York: E. P. Dutton, p. 3, 1979). La idea de forma está en el centro de la epistemología sistémica y de su derivado necesario, la teoría de la observación. Ninguna observación puede ser hecha sin trazar a la vez y en un mismo acto una distinción. Consecuencia de esto es la imposibilidad de generar enunciados absolutos sobre la teoría y la praxis. Cada selección de uno de los dos lados de la forma es selección de un observador cuya disputa de validez no puede ser remitida a una instancia mayor. Una forma debe entenderse entonces "como límite, como la marca de una diferencia que obliga a dejar en claro cuál es el lado que se indica, esto es, en qué lado de la forma uno se encuentra” (Luhmann, Niklas: Die Gesellschaft der Gesellschaft, Frankfurt: Suhrkamp, p. 60, 1998). Sociológicamente visto, esto afirma la autonomía de los sistemas funcionales parciales de la sociedad (economía, derecho, política, medios de comunicación de masas) y de sus actores corporativos (empresas, asociaciones, grupos de interés): cada uno de ellos sigue ante todo sus propias formas y es, en principio, indiferente a los modos de observación de los demás. De este hecho deriva finalmente la utilidad de una teoría sociológica de la orientación, en tanto permite hacer visible y coordinar las selecciones practicadas por cada observador, ya sea se trate de sistemas funcionales o actores corporativos. (N. del T.) 
zada, ha crecido a la altura de las exigencias que las sociedades desarrolladas ponen ante ella.

Conscientemente utilizo aquí el concepto de democracia no únicamente como principio de dominación, sino, de un modo general, como idea de auto-organización de sistemas sociales complejos. Con esto, es claro que la reflexión en torno a la democracia moderna desarrollada por sus filósofos y precursores (Hobbes, Locke, Rousseau, Montesquieu, Madison y otros) no sólo puede ser reducida a la pregunta por la dominación política, sino que más ampliamente apunta al problema del orden social, presente en cada instante de la arriesgada empresa de ingreso a la modernidad.

Contrariamente a la posición defendida por Rudolf Stichweh (1995) en apoyo a Luhmann, entiendo la sociedad moderna no precisamente como una sociedad mundial, sino, tanto ahora como antes, bajo la forma de una unidad normativa territorialmente delimitada de (auto)organización social. Sólo unidades normativas territoriales están en posición de generar autónomamente las estructuras fundantes de su autoorientación. La autonomía es, en este sentido, una condición imprescindible para la formación de sistemas sociales autorreproductivos. Dado que no existe una instancia, un procedimiento o reglas determinadas que establezcan normas de auto-orientación vinculantes para el mundo en general, carece de sentido hablar de una sociedad mundial. Si tales reglas existieran, la unidad de la totalidad social o la totalidad de las comunicaciones alcanzables sería 'el mundo', no la sociedad. Por otro lado, el surgimiento contemporáneo de corrientes fundamentalistas en ciertas partes del mundo ha puesto incluso en duda que las comunicaciones tengan hoy un alcance global.

Esta construcción conceptual permite también examinar, en una perspectiva comparada, las cualidades sistémicas de la auto-organización y la auto-orientación de distintas sociedades en relación a su adecuación, capacidad de rendimiento y relaciones costo-beneficio. Si el análisis sistémico no desea apartarse de preguntas relevantes en un sentido práctico, la formación de sus conceptos no puede seguir solamente en una dirección teórica.

Este acceso al tema permite ahora - luego de que la modernidad, al menos en el primer mundo, ha logrado expandirse - plantear ciertas interrogantes a la democracia. La cuestión es que la democracia por sí sola ya no garantiza el orden de las sociedades complejas. Ciertamente este tema es algo delicado. Por ello es necesario dejar en claro desde un comienzo que este texto no propone una renuncia a la democracia, sino su revisión desde el punto de vista de su idoneidad como modelo de orientación social, cuestión que, por lo demás, ya habían constatado King y Schneider (1991, p. 69) 
en su informe de 1991 al Club de Roma: "La democracia no es una receta patentada. No domina todo y no conoce sus propios límites”.

Antes de entrar a discutir los límites del modelo democrático y sus actuales posibilidades de orientación y coordinación social, es recomendable examinar más de cerca sus fortalezas. Charles Lindblom (1965) ha emprendido su vehemente defensa como principio de orientación social. Destaca, ciertamente con razón, la descentralización del procesamiento de información y de la toma de decisiones, su estructura de control no jerárquica, un proceso de construcción de opinión interactivo y discursivo, y un juego pluralista de fuerzas carente de funciones finales preestablecidas 'desde arriba'. Tales rasgos, entre otros, se observan de modo especialmente claro al contrastar los órdenes democráticos con el carácter abstruso de los sistemas autoritarios.

Sin embargo, la euforia en torno a la inteligencia de la democracia no se mantuvo por mucho tiempo. Doce años después Lindblom (1977, p. 344) se pregunta con preocupación si la democracia tiene algún futuro. En un estudio, que sugestiva y expresamente apunta en dirección de una teoría de la orientación social, el autor compara tres métodos fundamentales relativos a tal problemática: intercambio, autoridad y persuasión. A partir de un bien fundado escepticismo acerca de las capacidades de orientación del mercado y de los regímenes autoritarios, llega Lindblom a una curiosa sobrestimación de la capacidad de orientación social de la persuasión, estructurada en lo que llama sistemas preceptorales ${ }^{\mathrm{c}}$ (aunque vista desde una posición actual, esta sobrestimación es históricamente comprensible). No es posible por ahora entrar más profundamente en esto. Interesante es, en todo caso, que Lindblom vea el defecto central de la democracia, como principio de orientación de las sociedades modernas, en el hecho de que los procesos de adaptación e intercambio del juego democrático formal, modelados por el mercado, no logren corregir la alta preponderancia de actores organizados, ante todo de las grandes corporaciones. Con ello se derrumba la idea fundante de la orientación social democrática, a saber, el uso de inteligencia descentralizada en función del bien colectivo y la protección de los múltiples decisores frente a los excesos de poder de actores individuales.

${ }^{\mathrm{c}}$ Un sistema preceptoral, en la definición de Lindblom, está basado en la persuasión tanto como el mercado lo está en el intercambio y el sistema político en la autoridad. Se trata, en su forma típico-ideal, de un manejo unilateral y masivo de la opinión "en la que una elite dominante iluminada entrega reglas de conducta [...] convencida de que una mayor racionalidad logrará cambiar a los individuos”. Lindblom, Charles: Jenseits von Markt und Staat. Eine Kritik der politischen und ökonomischen Systeme (New York: Basic Books, 1980), p. 101. (N. del T.) 
En contraposición a Lindblom, no nos ocupamos actualmente de un conflicto claramente delimitado entre la legitimación democrática y la lógica de rentabilidad capitalista, sino de la dinámica de interacción entre sistemas de lógicas particulares, los cuales aún no logran ver su propia ceguera y se asumen a sí mismos independientes de sus múltiples restricciones.

La democracia, como principio de orientación política, adquiere un carácter defensivo tan pronto el propio sistema político no puede ya dominar la sociedad desde la cima de un orden jerárquico. La democracia política entra así en competencia con una variedad de formas de orientación en principio equivalentes, aunque con lógicas diferenciadas. Esto tiene lugar en tanto otros sistemas funcionales - ante todo la economía, la ciencia, los medios masivos - logran escapar a la subordinación política y ponen con ello en entredicho de modo fundamental el principio estructural de una diferenciación funcional con primacía de un único sistema funcional. La pregunta es, entonces, la siguiente: ¿cuál es el principio de orientación válido para la sociedad entera?

Con esta pregunta nos situamos en los terrenos de una de las paradojas centrales asociadas a los mecanismos de orientación de las sociedades modernas. En tal sentido, la democracia 'política' ha de ser excluida como modelo de orientación social general si no se desea imponer, contra la lógica de la diferenciación funcional, es decir, contra la lógica de la modernidad misma, un primado de la política frente a los otros sistemas funcionales. A la vez, cada forma 'no democrática' de orientación social ha de ser excluida si no se quiere, nuevamente contra la lógica de la modernidad, volver atrás en cuanto a los logros en derechos humanos y los referidos al uso de la diversidad individual. Frente a esto, y como forma de escapar de la paradoja, queda tan sólo una revisión de la idea de democracia en cuanto modelo de orientación social.

El debate en torno a la ingobernabilidad ${ }^{\mathrm{d}}$ ha puesto de relieve que la política democrática por sí sola no protege de la falta de desarrollo ni de las catástrofes derivadas de los propios procesos de orientación social. La for-

${ }^{\mathrm{d}} \mathrm{El}$ concepto de ingobernabilidad constituye una fórmula conservadora referida a los problemas regulativos enfrentados por el Estado, a partir especialmente de los años sesenta y setenta. Estos problemas tuvieron su origen en la expansión de las áreas de influencia de actores corporativos (sindicatos, consorcios, asociaciones) en el contexto de un capitalismo tardío y en la falta de capacidad del Estado para controlar y mantener el orden social. Como contraparte, la teoría crítica comprendió la ingobernabilidad bajo la fórmula de una crisis de legitimación o de sentido, la teoría de sistemas lo hizo como sobrecarga comunicativa de los sistemas funcionales y el neocorporativismo liberal o social (Lembruch, Schmitter) sustituyó la preocupación conservadora en torno a la gobernabilidad por el problema de la coordinación y mediación de intereses. Véase nota g. (N. del T.) 
mación de la voluntad y la toma de decisiones democrática es cortoplacista y descuida sistemáticamente las autoamenazas sociales de mediano y largo plazo: "Los gobiernos prefieren soluciones políticamente útiles en el corto plazo y desatienden de modo sistemático las perspectivas de largo plazo. [G]obernar deriva regularmente a reiterados manejos de situaciones de crisis, o en otros casos, en un vértigo provocado por las urgencias en cuestiones financieras, sociales, en la balanza de pagos, desempleo, inflación y otras por el estilo” (King y Schneider, 1991, p. 104).

La predicción de Lindblom acerca de la inadecuación de las grandes corporaciones al marco democrático debe ser reescrita toda vez que la realidad de la democracia moderna, en cuanto sociedad de organizaciones, sólo deja la elección de negar tal realidad o de renunciar al modelo democrático. Hace ya tiempo no existen dudas razonables en torno al dominio que las grandes organizaciones ejercen no sólo en el estrecho espacio político, sino en la sociedad en general. De tal modo, el proceso político resulta de la interacción estratégica entre una variedad de organizaciones públicas y privadas:

Una consecuencia importante de este desarrollo es la creciente fragmentación del poder que afecta la capacidad de acción interna y externa y el manejo de recursos de organizaciones formales. Concretamente, se debe pensar en grandes empresas, sindicatos, asociaciones económicas o de médicos. En muchas áreas de la política, por tanto, el Estado ya no se vincula a una esfera pública amorfa o con cuasi grupos como las clases sociales, sino a actores corporativos que disponen de sus propias bases de poder. (Mayntz, 1993, p. 41.)

Es un hecho que esto aumenta la intransparencia y los problemas de orientación social de las democracias modernas ${ }^{\mathrm{e}}$. Pero ¿̇e debe por ello renunciar al modelo democrático? En sociedades altamente diferenciadas, sistemas como la política, la economía, la ciencia, la educación o el sistema

\footnotetext{
${ }^{\mathrm{e}}$ En un contexto sociológico sistémico el concepto de intransparencia apunta a la imposibilidad de observar las operaciones internas de esferas autónomas. Cada sistema o actor corporativo es, en el proceso de deliberación que conduce a decisiones de acción, intransparente frente a otros. Subyace en este hecho el principio de observación supuesto en la teoría de la forma, descrita en la nota b. La intransparencia representa el núcleo de la paradoja a la que se enfrenta en la modernidad tardía la praxis democrática, pues si pretende disolverla, hacer visible lo invisible, corre el riesgo de generar vínculos de control y dependencia con sistemas y actores que, a raíz de ello, pierden su autonomía. En tanto, si libera esa intransparencia a su propio operar, pierde toda posibilidad y expectativa de coordinación social. El resultado es su limitación, su reducción a la disputa del poder entre gobierno y oposición. (N. del T.)
} 
de salud han alcanzado gran autonomía y complejidad. Su modo de operación, esto es, los modelos y reglas estructurales de sus comunicaciones internas, se dirigen primariamente hacia una regulación interna, y sólo en segunda instancia hacia condiciones externas. El modo de operación de un sistema especializado atiende, en primer término, a la lógica del mismo sistema. De este modo, la economía reacciona sensiblemente a las fluctuaciones en los montos de dinero o a las tasas de inflación, pero no lo hace frente a millones de desempleados, pues éstos no representan estrictamente un dato económico. Así también, el sistema político reacciona con rapidez a datos propiamente políticos, como elecciones, desplazamientos de votantes o nuevos actores corporativos, pero responde muy lentamente a ciertas constelaciones de problemas objetivamente apremiantes, como el armamentismo, la destrucción del medio ambiente o los riesgos tecnológicos, pues éstos no se orientan de modo inmediato a criterios políticamente relevantes.

Frente a esta autorreferencia y autolimitación de los sistemas parciales especializados funcionalmente, la teoría política contemporánea parte todavía desde una comprensión expansiva de la política, situándola en la cima jerárquica de la sociedad, y atribuyéndole así el primado respecto de su conducción. En este sentido, la política, como parte de la sociedad, es responsable por su totalidad, y debe por ello estar en posición de manejar, a través de intervenciones directas, a las otras esferas sociales parciales. Tal concepción contemporánea de un Estado de bienestar intervencionista acentúa así la capacidad de la política para obtener, desde fuera, determinados resultados en el interior de las respectivas esferas.

Sin embargo, si los cambios y transformaciones estructurales son, en primera instancia, asuntos internos de sistemas corporativos autónomos, ellos logran, gracias a su autonomía operativa, un espacio de decisiones que los convierte en actores estratégicos al interior de la sociedad. Ésta es una forma activa de sociedad, un sistema con una dinámica propia, que se transforma a sí mismo (Etzioni, 1971, p. 121) y que alcanza este nivel como consecuencia de una combinación no-regulada de sistemas parciales activos.

Las sociedades desarrolladas producen con esto el riesgo de una dinámica centrífuga incontrolable, donde los sistemas funcionales especializados (como la economía, la ciencia o el sistema de salud) afectan la cohesión del todo. La política no puede generar esta cohesión, pues le faltan los conocimientos para su orientación y los medios para la ejecución de sus programas. La sociedad pierde entonces coherencia y aparece el peligro de la desintegración: un riesgo manifiesto frente al cual la política es impotente (armamentismo, altos costos del sistema de salud, colapso del sistema de transporte, etc.). 
Una solución teórica y práctica de este problema remite a estructuras de decisión interconectadas corporizadas en sistemas de deliberación, los cuales reúnen a actores socialmente relevantes frente a determinados problemas (para esto, véase sección 4). Como siempre, esta salida adopta una forma concreta: ella supone que el sistema político ha perdido su posición de cumbre jerárquica de las sociedades modernas y debe dar paso a una revisión del modelo de orientación democrática.

\section{El desafío del mercado}

Desde una perspectiva sociológica, el mercado moderno es un fenómeno desviante. Construido sobre la figura del homo oeconomicus, en el que individuos aislados intercambian bienes privados según un cálculo racional, el mercado supone la transformación de la comunidad tradicional en una sociedad moderna funcionalmente diferenciada. Ésta es una condición para la liberación del cálculo económico de los lazos familiares, de la amistad, de la moral o de la religión. En lugar de estos lazos tradicionales, tienen lugar otros vínculos que sólo logran garantizar la estabilidad del mercado. Se trata de las famosas 'dimensiones no contractuales del contrato', es decir, el marco de regulación institucional que crea un espacio apropiado para esta improbable construcción que es el mercado: esto es, un orden político 'moderno' de libertades sustentadas procesalmente en un sistema jurídico igualmente 'moderno'. Mark Granovetter (1992) ha apuntado con especial claridad que incluso los mercados modernos están inscritos en instituciones sociales.

Asimismo, los propios economistas aceptarán que un mercado guiado por precios no puede funcionar sin un conjunto de reglas generales de validez colectiva, reglas que en una sociedad moderna sólo pueden ser entregadas por la política: seguridad, libertad de contrato, derechos de propiedad, garantías legales, autolimitación del poder político, etc. Dentro de este orden, la especial capacidad del mercado se comprueba en el despliegue de una coordinación extremadamente rápida y de bajo costo entre oferta y demanda, situada más allá del mecanismo de precios y bajo la condición, en ningún caso obvia, de un libre acceso y una libre renuncia a la participación.

La duda en torno a los costos favorables del mercado comienza ahí donde las transacciones económicas tensionan el marco de relaciones libres, simples, de corto plazo y directas entre oferentes y demandantes. El mercado fue un descubrimiento genial para reducir la complejidad de las 
relaciones de intercambio a 'elecciones racionales'. Pero evidentemente este espacio no ha quedado por mucho tiempo libre de la acción de la evolución, opera ahora como invernadero para la producción de nueva complejidad. Mientras las relaciones de mercado se someten más fuertemente al poder insaciable de la complejidad, mientras más complejos llegan a ser los productos, las formas de producción, las relaciones de intercambio, los horizontes temporales y los cálculos de costo-beneficio de oferentes y demandantes, más problemático se hace suponer que el mercado funcione prácticamente sin costos de transacción (sin demoras ni esfuerzos de coordinación) y que, por tanto, es favorable en tales términos. Un 'tiempo invisible’ y una 'mano invisible', como rasgos constitutivos de un mercado ideal, no pueden salir airosos frente a los desafíos de la complejidad.

Es sintomático que la formulación más clara de esta duda no haya sido desarrollada en el marco de una teoría del mercado, sino en el de una teoría de la firma. En 1937, Ronald Coase publicó su clásico estudio “Teoría de la Firma” (1937, pp. 386-405), cuyo fundamento era la admiración que a Coase le causaba el hecho de que el mercado no fuera la única instancia de coordinación de las transacciones económicas (como la propia teoría del mercado lo indica), sino que las firmas asumieran una parte importante de la coordinación necesaria.

O. Williamson $(1975,1985,1991)$ redescubrió a Coase a comienzos de los años setenta. Coase y Williamson son relevantes para nuestro tema, pues apuntan directamente hacia una comparación de las capacidades de coordinación del mercado y de la jerarquía. Si de ello resultara que para transacciones e interacciones complejas la jerarquía efectivamente es un modelo de orientación superior, la autorregulación democrática se vería entonces en serios problemas.

Coase y Williamson no hablan en todo caso de democracia, sino del mercado como un modelo opuesto a la jerarquía, pero esto es usual entre los economistas, como también lo es el miedo de desacreditar la democracia como modelo al preferir la jerarquía. Para una observación sociológica, y en especial al analizar teóricamente los problemas de orientación social, el pathos democrático carece de valor si no se justifica de buen modo por qué y bajo qué aspectos debe preferirse la democracia como modelo de orientación de las sociedades complejas.

Una afinidad importante entre democracia y mercado consiste en que ambos son formas homólogas de coordinación caracterizadas por la autoorganización, la descentralidad, la distribución de la inteligencia, una amplia autonomía de los sistemas parciales, el carácter extendido de la toma de decisiones, su fácil examen y especialmente una igualdad formal de los deci- 
sores (o electores). A la vez, ambas instancias se caracterizan por su lógica de decisiones a corto plazo, el carácter difuso de la responsabilidad, la predisposición hacia modas, tendencias, hacia la propaganda de los medios masivos, y en especial por una capacidad inmanente y difícil de controlar para ponerse en peligro a sí mismas por medio de una densificación en el número de organizaciones, monopolios o costos ocultos.

En lo referido a la lógica de mercado, estos rasgos han recibido un nuevo y fuerte impulso desde la confluencia de tres movimientos de carácter global:

1. La implosión del bloque socialista ha liberado la competencia global entre sistemas socioeconómicos distintos de su orientación dominante hacia conflictos militares. Con esto, la aún agitada carrera tecnológica adquiere una fuerza desacostumbrada y un perfil político. Todas las argumentaciones justificatorias referidas al uso de personal, energía, inversiones y tiempo de atención, al igual que aquellas orientadas a apoyar el desarrollo de técnicas y tecnologías militares estratégicas, llegan a ser así obsoletas o incluso absurdas. Esto adquiere validez especialmente para Estados Unidos, país que principalmente ha llevado el peso - y también algunas ventajas- de su posición hegemónica en los esfuerzos disuasivos de Occidente; aunque también es válido para Europa, en tanto el presagio de una relación triádica (Estados Unidos, Europa, Japón) se ha transformado dramáticamente en un balance precario entre cooperación y competencia.

2. Las cada vez más agudas disonancia y desigualdad de esta relación triádica provocadas por la dinámica tecnológica, financiera y económica de Japón carecen de contrapeso. En pocos años Estados Unidos ha pasado de ser un gran acreedor a un gran deudor del mercado financiero internacional. En Europa, en tanto, se combinan los efectos del modelo cada vez menos sustentable del Estado de bienestar y de una clara política económica proteccionista que reedita parcialmente la 'euroesclerosis' de los años setenta, esta vez más en el área de las innovaciones científicas, tecnológicas y comerciales que en el campo institucional. En 1990, sólo el 17\% de las exportaciones europeas estuvieron constituidas por productos de alta tecnología, ante el 27\% de las japonesas y el 31\% de las norteamericanas; a la vez Europa utiliza cerca de un tercio de todos los bienes electrónicos y produce sólo el 10\% de ellos (Linkohr, 1993).

3. Los altos gastos destinados al desarrollo de nuevas tecnologías nucleares afectan en distintas dimensiones la regulación laissez-faire de una competencia orientada por los mecanismos de mercado. Esto es visible especialmente en lo que respecta a las proyecciones temporales, la intensidad de investigación, las inversiones y el riesgo. Las perspectivas tempora- 
les de corto plazo a las que obliga el mercado — particularmente el mercado de finanzas - no son problemáticas en tanto se trate de alfileres, zapatos o carrozas de caballos. Sin embargo, ellas devienen en gastos prohibitivos cuando se trata de aviones, chips de 256 megabytes, autos, satélites o grandes buques petroleros. Algo similar sucede con las inversiones de capital, las iniciativas de inversión y desarrollo, las estimaciones de riesgo y la infraestructura pública (incluyendo en ella desde ingenieros especializados hasta instancias para el manejo y control de nuevas tecnologías). Por esto, sólo unos pocos actores privilegiados pueden participar de las tecnologías de punta, lo que agudiza la desigualdad global.

Mientras los preceptos de la economía de mercado y el 'libre comercio' se hacen cada vez más sagrados en el discurso político oficial, es indudable que la idea de un mercado regulado por una 'mano invisible', desarrollada para las condiciones económicas de la primera revolución industrial, ha llegado a ser insuficiente. El marco de condiciones económicas ha cambiado en aspectos fundamentales:

Actores: No son ya los individuos, en cuanto sujetos económicos, los que determinan los sucesos del mercado, sino las organizaciones, consorcios, holdings, conglomerados, keiretsus ${ }^{\mathrm{f}}$, y ante todo redes organizacionales bajo la influencia de instituciones financieras y actores políticos. En una perspectiva histórica, esto puede ser interpretado como un giro hacia un nuevo mercantilismo. Para una observación sociológica sistémica, se trata más bien de un cambio multidimensional de la economía como un todo, cambio en el cual la dinámica tecnológica y los riesgos sociales de los procesos económicos obligan a una intervención política. Consecuencia de esto es la difusión y desplazamiento de los riesgos económicos hacia la política.

Bienes: La clara división de bienes privados y bienes públicos (Musgrave, 1978, pp. 57 y ss.) y la correspondiente separación de tareas entre economía y política requieren de una revisión no sólo en tanto el uso de bienes privados en las sociedades de masas se suma a los riesgos existentes, sino también porque una tercera y especialmente interesante categoría de bienes — que hace difusos los límites entre economía y política- se ha hecho un lugar entre los bienes privados y los bienes públicos. Llamo a

\footnotetext{
${ }^{\mathrm{f}}$ Keiretsu es la denominación de la estructura empresarial japonesa moderna. Su particularidad consiste en el establecimiento de relaciones laterales en forma de red entre instancias altamente diferenciadas aunque acopladas en sus estructuras productivas. Se trata de la reinterpretación del Zaibatsu, la organización jerárquica tradicional japonesa previa a la Segunda Guerra Mundial. (N. del T.)
} 
esta categoría bienes colaterales (Willke, Krück y Thorn, 1995). Éstos se caracterizan por poseer rasgos de bienes tanto privados como públicos, aunque aquello que los define de modo más preciso es que no son producidos por el mercado mientras no se garantice que quienes no han participado en su elaboración estén impedidos de su uso futuro.

Los bienes privados son aquellos que la política puede producir pero no desea hacerlo, traspasándolos por ello al mercado; los bienes públicos son los que la política puede y desea crear, mientras que los bienes colaterales consisten en aquellos bienes que la política, en función de un interés público, desea producir, aun cuando por sí sola no puede hacerlo, sea porque los actores políticos carecen de conocimientos, dinero o de apoyos. Ejemplos de bienes colaterales son las precauciones contra riesgos de salud, la eliminación de desechos tóxicos, la capacitación y el perfeccionamiento laboral. Actualmente se desarrollan bienes colaterales principalmente en el área de las nuevas infraestructuras 'inteligentes' (redes de datos de alto rendimiento, sistemas de coordinación de tráfico, sistemas de distribución energética), los que, al contrario de los sistemas infraestructurales conocidos hasta hoy, han llegado a ser demasiado complejos, costosos y sujetos a múltiples determinaciones como para que puedan ser producidos en la forma de los bienes colectivos clásicos. El riesgo específico de los bienes colaterales es el de la no producción: si faltan las condiciones para una coordinación positiva, se llega a un juego de suma negativa en el que todos pierden y en el que ningún actor está en situación de cambiar las reglas.

Reglas: Se trata fundamentalmente de reglas para la producción de bienes colaterales para los cuales ni el rechazo del mercado ni el del Estado son respuestas aceptables. Tales reglas apuntan a una forma específica de complementación entre competencia y cooperación, en ocasiones en las que la primera no genera el bien y la segunda pone en peligro el propio principio de la competencia económica. Lo que en períodos preindustriales era obvio en cuanto a cuestiones asociadas al riesgo y la solidaridad, y lo que como principio de solidaridad y seguridad marca el inicio del Estado social, debe ser hoy, en las sociedades industriales occidentales, legitimado y fundamentado para cada nuevo caso. De ello resulta un significativo efecto para la competencia internacional: si un actor relevante logra formular y mantener esas reglas para su área de acción, entonces la situación pierde equilibrio para los demás actores, quienes se ven obligados a participar en un juego cuyas reglas no dominan.

Así, tiene lugar una transformación fundamental de la función política: ésta pasa de la regulación a la mediación. Las condiciones de posibilidad 


\section{www.cepchile.cl}

de la intermediación política —en relación a la problemática tratada en el debate neocorporativista ${ }^{\mathrm{g}}$ — no han sido aún ampliamente aclaradas. Tres modelos teóricos se encuentran en competencia: el enfoque de un discurso político fundamentado en intereses con capacidad de generalización (Habermas); el enfoque de una autorregulación radical sobre la base de siste-

${ }^{\mathrm{g}}$ Lo que puede ser llamado debate neocorporativista es el intento, principalmente en países de Europa del Norte, de generar estructuras de mediación y formulación de políticas para la resolución de conflictos entre diversos grupos de interés. En tales estructuras, el Estado renuncia a su rol de control y ejecución y adquiere un papel de conciliación y supervisión de los acuerdos suscritos, acuerdos cuya implementación es responsabilidad de los propios afectados, no del Estado. En los años sesenta y setenta, años que habían puesto el problema de la ingobernabilidad en una posición central del debate político, el pluralismo norteamericano parecía algo ajeno a una Europa continental que veía crecer sus instituciones intermedias de modo acelerado bajo el alero de un Estado social centralizante, y el sindicalismo, en tiempos de 'guerra fría', se presentaba más bien como antesala del marxismo. Al distanciarse de su versión autoritaria, el neocorporativismo liberal (Lembruch), social (Schmitter) o también pluralismo corporativo (Maier) ofreció una salida intermedia al problema conservador de la ingobernabilidad. En un contexto capitalista tardío, la crisis de legitimidad exigía la búsqueda de un nuevo acuerdo, y el neocorporativismo parecía aportar un pensamiento práctico distante tanto de una reburocratización del Estado como de su destrucción bajo la tesis del Estado mínimo. De cualquier manera el neocorporativismo no se alejó dogmáticamente de las concepciones pluralistas. Mantuvieron puntos de acuerdo importantes principalmente en lo relativo a las pretensiones de autonomía de las esferas extra-estatales. Se distanciaron, sin embargo, en el rol que asignaron a éstas, como señala Von Beyme, "En el modelo corporativista, los grupos de interés no sólo tienen influencia en las decisiones de un Estado entendido más o menos como una 'caja negra', como en el modelo pluralista de los grupos de presión, sino que participan además en la formulación, elaboración e implementación de las decisiones estatales y en todas las fases del proceso de decisión de los proyectos legislativos” (Beyme, Klaus von: Interessengruppen in der Demokratie, München: R. Piper \& Co. Verlag, 1980, p. 47). Esta distinción separó también a las dos corrientes principales del neocorporativismo, la de Lembruch y la de Schmitter. Mientras para Schmitter el neocorporativismo puede ser definido como un "sistema de mediación de intereses" (Schmitter, Philippe: "Interessenvermittlug und Regierbarkeit”, en Alemann, Ulrich von (ed.), Verbände und Staat: vom Pluralismus zum Korporatismus, Opladen: Westdeutscher Verlag, pp. 92-114, 1979), para Lembruch éste constituía "un modelo institucionalizado de formación de políticas en el cual grandes organizaciones cooperan unas con otras, así como con las autoridades públicas, no sólo en la articulación (o incluso en la intermediación) de intereses, sino —en su forma desarrollada - en la 'adjudicación autoritativa de valores' y en la implementación de políticas" (Lembruch, Gerhard: "Liberal Corporatism and Party Government", en Comparative Political Studies, Núm. 10, 1977, pp. 91-126.). A ambas tradiciones las unía, sin embargo, un origen común, caracterizado por la respuesta al dilema conservador de la ingobernabilidad, por el reconocimiento del desarrollo de instituciones intermedias y por la necesidad de una coordinación equitativa entre una multiplicidad de actores diversos, incluido el Estado (Willke, Helmut: Entzauberung des Staates. Überlegungen zu einer sozietalen Steuerungstheorie, Königstein/Ts.: Athenäum Verlag, 1983, pp. 140 y ss.). (N. del T.) 
mas autopoiéticos (Luhmann) y el enfoque de una orientación contextual descentralizada de sistemas complejos (con distinta importancia: Mayntz, Scharpf, Willke).

Cuál de estos caminos se impondrá en la revisión de la democracia, no está aún decidido. Es de esperar que en las sociedades desarrolladas se acentúe la regulación de la competencia y paralelamente surja un interés por reglas de coordinación óptimas. Mientras tanto, las sociedades subdesarrolladas seguirán siendo dependientes en este aspecto, pues carecen de los medios para desplegar perspectivas de largo plazo.

\section{El desafío de la jerarquía}

Contra todo pathos democrático, la democracia está estrechamente ligada a la jerarquía y no puede prescindir de los mecanismos de orientación de las organizaciones jerárquicas. Parece inimaginable que los ministerios, las burocracias, las reparticiones públicas, la policía o la armada pudieran llegar a organizarse de modo democrático. ¿Por qué?, ¿cuáles son las ventajas de la jerarquía como principio de orientación y cómo llega a legitimarse en vista del evidente carácter antidemocrático e inhumanidad del principio en sí?

Estas preguntas se plantean no sólo a nivel de la sociedad como un todo, sino también, bajo el nuevo impulso que significó el fin del socialismo a nivel de los sistemas funcionales y de los regímenes internacionales. En lo que respecta a unidades militares o carcelarias, el asombro asociado al empleo de modelos de organización jerárquicos puede ser aún controlado, pero ¿por qué deben estar jerárquicamente estructurados los hospitales, las universidades, las empresas, los monasterios, los clubes deportivos, las escuelas y las familias? ¿Qué hace a la jerarquía tan exitosa que no pueda ser imaginada organización alguna sin componentes de orden jerárquico?

La respuesta es efectividad y eficiencia en el cumplimiento de tareas. Ciertos tipos de tareas ante ciertos tipos de objetivos son mejor desarrollados bajo la forma de la jerarquía. Como Max Weber lo ha mostrado en su análisis de la burocracia, las ventajas de la jerarquía son efectivas cuando los problemas a resolver adoptan la forma de secuencias simples, lógicas y binarias, divisibles en pasos individuales y donde las soluciones parciales confluyen en una solución general. Se trata de problemas amplios, aunque claramente delimitados, a menudo complicados, pero 'bien ordenados', no solucionables en forma individual y relevantes colectivamente, cuya solución requiere de la acción organizada y ordenada de agentes especializados y competentes (Weber, 1972, p. 560 y ss.). 
Weber pone en estrecha conexión el tipo de tareas y su forma óptima de llevarlas a cabo. Su punto de referencia para la organización de la actividad estatal y el desarrollo de tareas son las grandes comunidades de tareas, esto es, la producción de bienes colectivos en un entorno de condiciones proporcional, visible, calculable y sólo paulatinamente cambiante. Su concepto de complejidad está impregnado del modelo de las máquinas de complejidad técnico-mecánica del siglo XIX. Su idea de racionalidad es aquella de una división jerárquica del trabajo desplegada sobre un orden lógico y secuencialmente ordenado de fines y medios.

Por un lado la descomposición jerárquica de las tareas y, por otro, la reagrupación jerárquica de los rendimientos parciales son precondiciones de una 'adecuación' de la estructura de tareas y la estructura de orientación. La concordancia de estas estructuras se destruye tan pronto entran en juego tareas complejas no susceptibles de descomposición ni agrupación jerárquica, pues entre las soluciones parciales de los distintos niveles existen relaciones laterales que exigen asociaciones transversales, coordinación supraestamental, discursos no jerárquicos, alta autonomía de decisión in situ, etc. Según Herbst (1976: pp. 18-21) estas relaciones pueden ser representadas esquemáticamente del modo siguiente (véanse Figuras $\mathrm{N}^{\circ} 1$ y $\mathrm{N}^{\circ} 2$ ).

Hoy es un hecho claro que las sociedades industriales modernas están cada vez más expuestas a tales problemas: destrucción del medio ambiente, riesgos químicos y biológicos, criminalidad, consumo de drogas, desempleo, problemas de la familia, etc. No es tan claro, sin embargo - $y$ en esto me detengo- , que en los contextos globales las tareas sean efectiva-

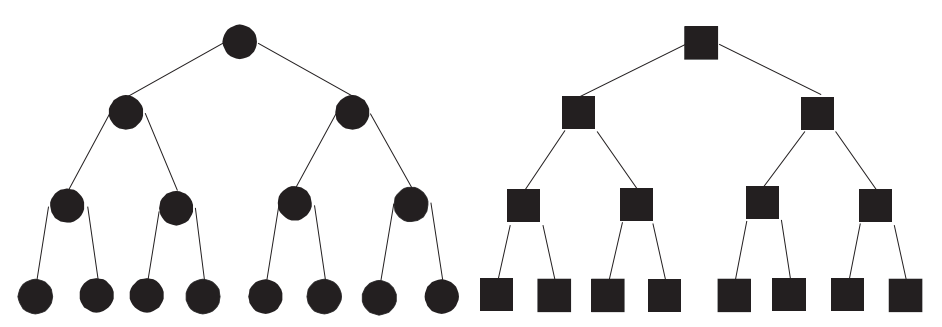

Estructura de tareas (segmento de tareas).

Estructura social (personas, secciones, etc.). 


\section{www.cepchile.cl}

FIGURA N ${ }^{\circ}$ 2: NO CONCORDANCIA DE LAS INTERDEPENDENCIAS LATERALES DEL SEGMENTO DE TAREAS

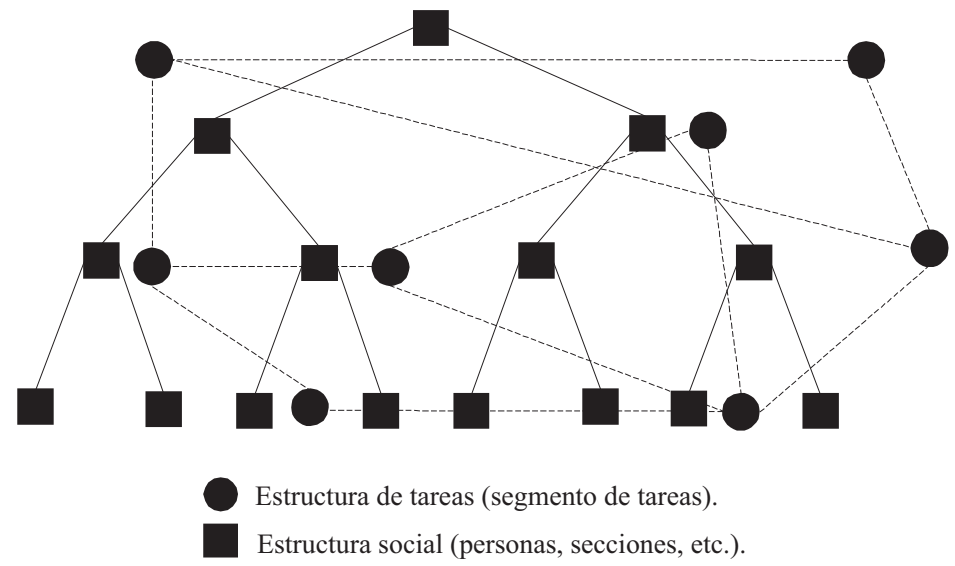

mente comprendidas como tareas complejas, cuyas soluciones deban ser encargadas al funcionamiento de un régimen internacional (Krasner, 1983). Me refiero, por ejemplo, a catástrofes ecológicas provocadas por accidentes de buques petroleros, a desplazamientos de refugiados, hambrunas, al terrorismo internacional, al crimen internacional organizado, a las crisis económicas, al subdesarrollo, a la sobrepoblación, etc. El punto decisivo es que tales tareas tampoco pueden ser tratadas adecuadamente en el marco de un régimen hegemónico, pues ellas, por un lado, demandan de tal hegemonía altos gastos financieros y militares y, por otro, conceden pocos incentivos y opciones para la autoayuda y la autonomía a los países dependientes.

Entre otros, D. Calleo (1987), antes del derrumbe del socialismo, ha dicho ya lo necesario en relación al primer aspecto. El segundo en tanto, ha sido por bastante tiempo sistemáticamente discutido, y fue ya tratado de modo ejemplar por R. Keohane (1984). Se acentúan aquí los paralelos en las transformaciones de los regímenes de coordinación y toma de decisiones al interior de las sociedades y entre ellas (regímenes globales). Estas transformaciones indican que las formas tradicionales de coordinación — democracia y jerarquía - han sido empujadas a los límites de su capacidad de conducción a raíz de los problemas complejos característicos de una modernidad tardía. Esto tiene lugar ante todo en una dimensión operativa y cognitiva. 
En el aspecto operativo, los aumentos de complejidad descritos afectan la capacidad de acción de los sistemas autoorganizados y autorregulados no sólo en cuanto crece el número de actores débiles y fuertes (por ejemplo, más países en la Naciones Unidas, más miembros en la Unión Europea, más lobbyists organizados en Washington, etc.), sino ante todo en el sentido de que las acciones y las estrategias de acción llegan a ser más contingentes, riesgosas y susceptibles de selección: el sistema produce opciones en una medida cada vez más difícil de coordinar.

Con esto, el mundo adquiere un grado de imprevisibilidad que exige formas y mecanismos adecuados de absorción de la inseguridad, de los entornos riesgosos y de asimilación de contingencia. Ciertamente las sociedades modernas tienen experiencia en ello. El proyecto de la modernidad no fue otra cosa que la disolución de una certidumbre religiosamente anclada por medio de una existencia y contingencia seculares. No obstante, muchas razones apuntan al hecho de que el instrumental desarrollado para esa transformación —ante todo el derecho positivo, la jerarquía formal bajo los parámetros de la organización y la democracia como estructura de dominación— ha sido llevado al límite de sus posibilidades y capacidades.

Con relación a la dimensión cognitiva, el vertiginoso desarrollo que ha alcanzado la 'cientifización del mundo' no requiere de mayor fundamentación. En el entorno de cada acción y de cada decisión se necesita de conocimiento experto. Esto tiene validez tanto para personas como para el saber organizacional en sistemas expertos, mecanismos de reglas, bancos de datos, datos producidos por medio de programas, etc. Esta complejidad del conocimiento tiene consecuencias para la complejidad de las formas de organización en las cuales los problemas son formulados y trabajados, y presenta igualmente repercusiones decisivas en las nuevas desigualdades globales originadas por saberes distintos, infraestructuras de saber diversas y formas diferenciadas de organización del conocimiento.

El riesgo particular de organizar jerárquicamente el segmento relativo al cumplimiento de tareas, radica en la trivialización artificial de aquéllas, a fin de adecuarlas a las estructuras de solución jerárquicas existentes. Ante cualquier tarea compleja, esto conduce inevitablemente a una 'lógica del fracaso', cuyos costos en problemas transregionales o globales pueden rápidamente llegar a ser catastróficos. Aún no está claro cómo lograr una definición adecuada de problemas tales como la sobrepoblación, el sida, el hambre, las guerras tribales o la destrucción ambiental (véase la ilustrativa investigación de Dörner, D.: Die Logik des Mißlinges, 1989). 


\section{4. ¿Transformación de la democracia?}

Las redes de actores sociales y los sistemas de deliberación son un intento cada vez más serio por ir más allá de los límites de la democracia como modelo de orientación de los sistemas complejos ${ }^{\mathrm{h}}$. No por casualidad los sistemas de deliberación se adhieren en las superficies marginales de la democracia y la jerarquía, pues aquí se cruzan los requisitos de participación, de decisión y de imputación de la responsabilidad política con la obligación de tomar decisiones de largo plazo, competentes para áreas específicas y adecuadas a los problemas existentes. Ambos flujos se conectan en una solución orientada al bien común tan pronto como una distribución de competencias (manifiestas y ocultas) puramente formal provoca la oposición de actores secundarios.

R. Mayntz (1992, pp. 19-32) y F. Scharpf (1993) han generalizado la idea de coordinación a través de sistemas de deliberación y la han probado empíricamente en distintos espacios políticos. En el caso de las sociedades modernas, cuyos sistemas funcionales han generado una alta autonomía interna y una dinámica propia, se hace cada vez más necesaria la presencia de una coordinación horizontal entre sistemas de importancia similar y, en principio, equivalentes. Esto se agudiza a medida que la política pierde su rol hereditario de cima jerárquica de la sociedad y debe entrar en acuerdos con otros colectivos dotados de poder y sentido propios para, de ese

\footnotetext{
${ }^{\mathrm{h}}$ Enfrentado a los problemas de orientación social (variante liberal de la ingobernabilidad) en sociedades complejas, Willke, desde las categorías descriptivas de la teoría de sistemas, ve en lo que llama, siguiendo a R. Mayntz, sistemas de deliberación una posible solución a cuestiones legitimatorias. Acciones concertadas, comisiones, mesas redondas, asociaciones de naturaleza diversa, son descritas como las instancias que superan y reemplazan las prácticas de un Estado expansivo. Para Mayntz los sistemas de deliberación logran estabilidad "cuando existen reglas capaces de aportar a la definición de compromisos aceptables [...] Esas reglas pueden estar orientadas a intercambios puros, a formas de reciprocidad o a una distribución justa de los costos y beneficios de una decisión colectiva (o de una determinada solución). En cada caso se requiere, ante todo, de una limitación voluntaria de la libertad de acción de cada participante, a fin de que los intereses seguramente divergentes de otros participantes, así como las consecuencias de las propias acciones, sean tomadas en cuenta [...] Pero aún hay algo más en juego. Ahí donde un número limitado de actores corporativos en un área determinada - un sector político, económico o un área tecnológica- se han adaptado tranquilamente al cumplimiento de las reglas que limitan las acciones egoístas o arbitrarias, puede desarrollarse un modelo de identidades organizativas, competencias y esferas de interés mutuamente aceptado". (Mayntz, R.: "Policy-Netzwerke und die Logik von Verhandlungssystemen”, en PSV Sonderheft, Policy-Analyse. Kritik und Neuorientierung, ed. por Adrienne Héritier, Núm. 24/1993, pp. 27-28.) (N. del T.)
} 
modo, acceder a estrategias de solución de problemáticas sociales complejas: "El surgimiento de redes políticas tiene dos importantes implicancias: es signo de un Estado 'débil', pero indica a la vez sensibilidad hacia la alta complejidad de la dominación política y hacia la creciente necesidad de consenso en las sociedades democráticas modernas" (Mayntz, 1992, pp. 19-32).

Paralelamente a las redes de 'promoción' económica, se han establecido en la esfera política distintas formas de redes de políticas públicas, cuya innovación fundamental consiste en lograr procesos de acuerdo y coordinación entre actores tradicionalmente competitivos o indiferentes entre sí (Mayntz, 1993). Bajo la presión de las incontrolables dinámicas, riesgos y conjuntos de problemas generados por la acción política 'normal', todos los actores colectivos que participan en estos procesos sienten, al menos, una irrenunciable necesidad de control recíproco de su propensión al caos. En tanto se presenten condiciones favorables (para las cuales existe a menudo la percepción de una competencia externa amenazante) y toda vez que este tipo de 'coordinación negativa' apunte a una limitación de posibles daños, se probabiliza también el desarrollo de una 'coordinación positiva' de los actores vinculados en una red de políticas públicas (Scharpf, 1992, p. 101; Scharpf, 1993, pp. 57-83). Esto suena tan plausible e inocente como difícil es encontrar en la praxis una coordinación positiva, pues ella presupone confianza, autocompromiso, atención a intereses ajenos y una perspectiva por lo menos de mediano plazo, lo que precisamente constituye una excepción en la praxis de la política (aunque no sólo ahí).

$\mathrm{Si}$, no obstante, tales precondiciones están presentes - especialmente la intención de apuntar a resultados de provecho colectivo-, podemos entonces constatar con Renate Mayntz una transición desde la forma y lógica de redes hacia aquella de los sistemas de deliberación (Mayntz, 1992, pp. 27 y ss.). La ventaja de los sistemas de deliberación consiste en hacer compatibles la lógica fuertemente egoísta del mercado y la lógica altamente paternalista de la jerarquía. Puesto que las contradicciones de ambas lógicas no desaparecen, el proceso de compatibilización es siempre un acto de balance. Sin formas de orientación ingeniosas, los sistemas deliberativos degeneran rápidamente en simples relaciones de intercambio formadas a semejanza del mercado, relaciones en las cuales cada uno busca su propia ventaja de corto plazo; o, por el contrario, se transforman en organizaciones altamente reglamentadas que pierden rápidamente su agilidad, fluidez y capacidad de respuesta.

Para hacer más visible la diferencia, quisiera escoger primeramente dos dimensiones antagónicas y situar, en la matriz que resulta de su combi- 
nación, las formas principales de coordinación de sistemas complejos. Las dimensiones son autonomía y coherencia. En ellas contrastan notoriamente las formas de coordinación jerárquica y de mercado, mientras que las redes constituyen una tercera forma intermedia aunque independiente. La coordinación democrática o de mercado deja a los actores una máxima autonomía; una jerarquía monocrática (típico-ideal) permite una mínima autonomía. La coherencia, en el sentido de una misión orientada al logro de objetivos, tiene una fuerte presencia en la jerarquía; en cambio, en las formas de coordinación democráticas o de mercado, lo está en grado mínimo.

Las redes se sitúan en un área central respecto de ambas dimensiones. Entre los 'tipos puros' representados por la formas principales, hay almacenados una serie de modelos de coordinación híbridos. En términos simples esto puede observarse en la figura siguiente:

FIGURA N ${ }^{\circ}$ 3: $\quad$ COMPARACIÓN DE LOS PRINCIPALES MODELOS DE ORIENTACIÓN BAJO LAS DIMENSIONES DE AUTONOMÍA Y COHERENCIA

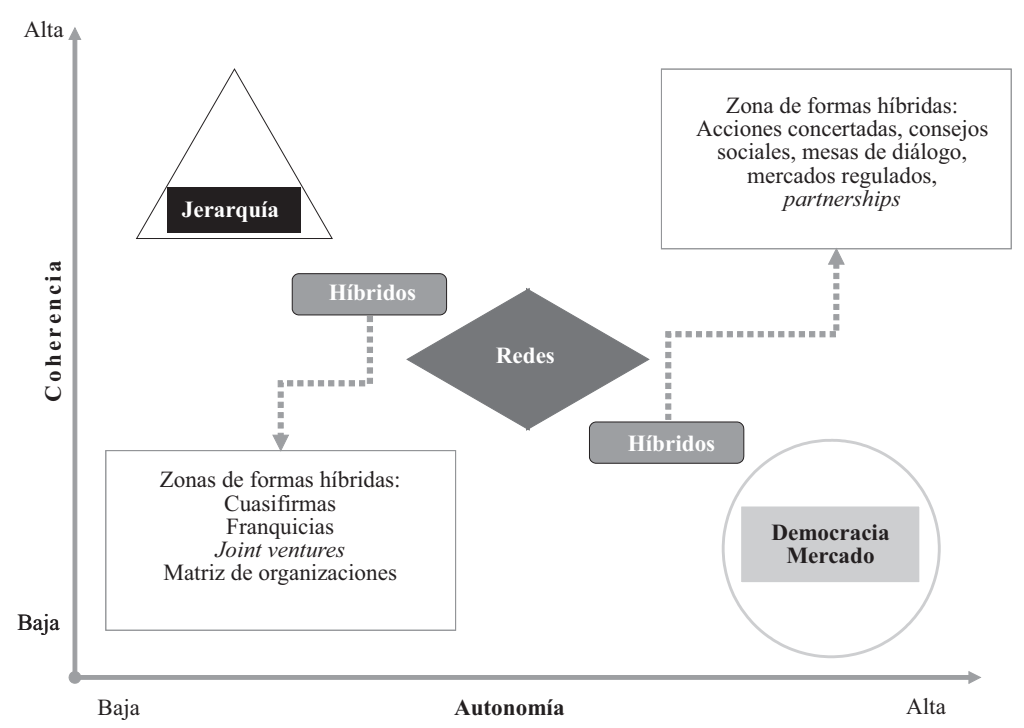

También en las relaciones internacionales, dada la multipolaridad del mundo, las redes y las formas híbridas entre democracia y jerarquía llegarán a ser cada vez más importantes. Sea como fuere, es cada vez más evidente la inevitabilidad de una pregunta que involucra a todos los actores, tal es: de 
qué modo es posible lograr un equilibrio entre las pretensiones de autonomía y coherencia sin trasladar nuestras catástrofes regionales o globales al próximo milenio.

\section{REFERENCIAS BIBLIOGRÁFICAS}

Calleo, D.: Beyond American Hegemony. New York: Basic Books, 1987.

Coase, R.: "The Nature of the Firm”. En Economica, Núm. 4, 1937.

Dörner, D.: Die Logik des Mißlinges. Reinbek: Rowohlt, 1989.

Etzioni, A.: The Active Society. New York: Free Press, 1971.

Garten, J.: A Cold Peace. America, Japan, Germany and the Struggle for Supremacy. New York: Times Books, 1992.

Granovetter, M.: "Economic Action and Social Structure: The Problem of Embeddedness”. En Zey, M. (ed.), Decision Making. Alternatives to Rational Choice Models. Newbury Park, Sage, 1992.

Herbst, P.: Alternatives to Hierarchies. Leiden: Nijhoff, 1976.

Keohane, R.: After Hegemony. Cooperation and Discord in the World Political Economy. Princeton N. J.: Princeton University Press, 1984.

King, A. y B. Schneider: "Die globale Revolution. Ein Bericht des Rates des Club of Rome”. En Spiegel-Special, Núm. 2, 1991, p. 69.

Krasner, S. (ed.): International Regimes. Ithaca and London: Cornell University Press, 1983.

Lindblom, Charles: The Intelligence of Democracy. Decision Making through Mutual Adjustment. New York: Free Press, 1965.

Lindblom, Charles: Politics and Markets. New York: Basic Books, 1977.

Linkohr, R.: "Hochtechnologie: Ein Schlüssel für die Wettbewerbfähigkeit”. En Das Parlament, Vol. 1.1.1993, 11, Núm. 1, 1993.

Mayntz, R.: "Modernisierung und die Logik von interorganisatorischen Netzwerken". En Journal für Sozialforschung, Núm 32, 1992, pp. 19-32.

Mayntz, Renate: "Policy-Netzwerke und die Logik von Verhandlungssystemen”. En PSV Sonderheft, Policy-Analyse: Kritik und Neuorientierung, Adrienne Héritier (ed.), $\mathrm{N}^{\circ}$ 24, 1993.

Musgrave, R. et al.: Die öffentlichen Finanzen in Theorie und Praxis. Vol. 1, Tübingen: Mohr, 1978.

Scharpf, F.: "Die Handlungsfähigkeit des Staates am Ende des Zwanzigsten Jahrhunderts”. En Kohler-Koch, B. (ed.), Staat und Demokratie in Europa. Opladen: Leske \& Budrich, 1992.

Scharpf, F.: "Positive und negative Koordination in Verhandlungssysteme". En PSV Sonderheft, Policy-Analyse: Kritik und Neuorientierung, editado por Adrienne Héritier, No 24, 1993.

Stichweh, Rudolf: “Zur Theorie der Weltgesellschaft”. En Soziale Systeme, Núm. 1, 1995.

Weber, M.: Wirtschaft und Gesellschaft. Tübingen: Mohr, 1972.

Williamson, O.: Markets and Hierarchies: Analysis and Antitrust Implications. New York: Free Press, 1975. 
Williamson, O.: The Economic Institutions of Capitalism. Firms, Markets, Relational Contracting. New York, London: Free Press, 1985.

Williamson, O. y S. Winter: The Nature of the Firm: Origins, Evolution and Development. New York, Oxford: University Press, 1991.

Willke, H., C. Krück y C. Thorn: Benevolent Conspiracies. The Role of Enabling Technologies in the Welfare of Nations. Berlin, New York: de Gruyter, 1995. 